\title{
Patterns of Changes in C-Reactive Protein (CRP) in Patients Performed Intestinal
}

Anastomosis Resection

Embong Wicaksono ${ }^{1}$, Sarup Singh ${ }^{1 *}$

${ }^{1}$ Department of Surgery, Faculty of Medicine, Universitas Sriwijaya, Indonesia

*Correspondence Author Email: sarupsingh@ gmail.com

\begin{abstract}
Introduction. C-reactive protein (CRP) is used as a marker of intestinal anastomosis leakage, its short half-life can be used as a predictor of intestinal anastomosis leakage. This study aimed to determine the pattern of increased preoperative and postoperative CRP in all patients undergoing bowel grafting.

Methods. This was an observational analytic study with a prospective cohort design of 20 patients undergoing intestinal anastomosis. Comparative analysis using the unpaired t-test, man whitney test and fisher test.

Results. The mean preoperative CRP serum up to the sixth postoperative day in the leakage group was higher than non-leakage, but there were no significant differences between the two groups $\left(\mathrm{p}_{\text {preop }}=0.852 ; \mathrm{p}_{\text {POH } 1}=0.791 ; \mathrm{p}_{\text {POH } 2}=0.634 ; \mathrm{p}_{\text {POH } 3}=0.507 ; \mathrm{p}_{\mathrm{POH} 4}=0.534 ; 0.507 ; \mathrm{p}_{\mathrm{POH} 5}=0.506 ;\right.$ p sensitivity (67\%) and specificity (65\%) in knowing the risk of anastomotic leakage.

Conclusion. An increase in CRP levels up to the third postoperative day is a marker of anastomotic leakage. CRP cut-off values> $170 \mathrm{mg} / \mathrm{L}$ on the second postoperative day have maximum sensitivity and specificity.
\end{abstract}

Keywords: c-reactive protein, intestinal anastomosis, resection 


\section{STS SRIWIJAYAJOURNAB OFEURGERY}

\section{Introduction}

Leakage anastomosis is a serious complication that occurs after a colorectal surgery. This problem is closely related to the increase in morbidity and mortality rates, the burden of treatment that increases with the length of time needed to treat complications due to leakage of the intestinal connection. ${ }^{1}$ The frequency of failure of the anastomosis varies depending on the location of the gastrointestinal tract. Anastomotic leak is an important initial complication. The incidence is reported to be $53 \%$, with leakage after colorectal anastomosis of $4-26 \%$ and mortality rates in the literature vary from 6-39\% .2 The incidence rate of anatomic leakage varies greatly in various countries. ${ }^{3}$ Incidence rate intestinal leaking or leakage anastomosis also has a different value based on the location where the action was taken. For anterior resection measures have a value of $12 \%$ $15.3 \%$ while for the overall resection of $4.3 \%-13 \% .{ }^{4}$

There are many risk factors associated with anastomosis leakage and most of them have also been published in various studies. The most important factors include gender, age, low anastomosis, history of malignancy, high American society of Anesthesiologist (ASA) value, length of time of operation, emergency surgery, history of radiotherapy and loss of blood during the operation. ${ }^{5}$ Diagnosis anastomotic leakage must be as early as possible for effective management. Delay in diagnosis of anastomotic leakage results in poor treatment. It would be very difficult for a surgeon to remain objective in considering the possibility of an anastomotic leak that they made themselves. Consulting a fellow surgeon for a second opinion in this matter is important and highly recommended. Diagnostic CT scan for suspected anastomotic leakage in the distal colon may be useful with additional contrast via rectal and intravenous, however imaging studies should not be performed in patients with hemodynamically unstable conditions. ${ }^{6}$

C-Reactive protein (CRP) is a protein that is produced in the acute phase by liver hepatocytes and increases during the inflammation process and has been widely used as an indicator of postoperative complications in abdominal surgery. Because of its short half-life (19 hours), CRP is a serum biomarker that can be relied upon to assess the occurrence of systemic inflammation response syndrome (SIRS) in surgical procedures or even as a marker of postoperative complications. Recently this protein has been used as an initial predictor of complications of abdominal sepsis after resection. ${ }^{7}$ In a 2011 study in Portugal, CRP had a sensitivity rate of $78 \%$ and a specificity of $86 \%$ for leakage of intestinal anastomosis in 


\section{STS SRIWIJAYAJOURNAB OFEURGERY}

postoperative patients on day $3 .{ }^{1}$ While in 2016 in the United Kingdom CRP has an $80 \%$ sensitivity and $80 \%$ specificity for leakage of intestinal anastomosis on day 3 by laparotomy, in laparoscopy intestinal anastomosis, the sensitivity is $75 \%$ and $70 \%$ specificity with leakage of anastomosis on day 2. ${ }^{8-10}$ Research conducted in Belgium in 2014 CRP increased within a few days after major surgery but was higher in infected cases. CRP values decreased in non-infectious cases on the $5^{\text {th }}$ postoperative day. No decrease in CRP value after postoperative day 4 was suspected of postoperative complications of infection. ${ }^{11-15}$

This study was aimed to evaluate the pattern of changes in C-Reactive Protein (CRP) in cases of intestinal anastomosis. It was expected that CRP can be a predictor and marker of intestinal anastomosis.

\section{Methods}

This study was an observational analytic study with a prospective cohort design to determine patterns of CRP changes in patients undergoing intestinal anastomosis resection. Research subjects (20 patients) were patients who had intestinal resection followed by intestinal grafting treated in Department of Digestive Surgery in Dr. Moh Hoesin general hospital who met the inclusion and exclusion criteria. Inclusion criteria are all patients who will be treated for intestinal resection and anastomosis, the age group of 18 years and over, willing to participate in research and sign an informed concern sheet. Exclusion criteria were patients with malnutrition and concomitant diseases.

Sociodemographic and clinical data from research subjects were collected, including sex, age, planned time of operation, type of disease causing anastomosis, location of anastomosis, and anastomosis technique. C-reactive protein examination was conducted at the Clinical Pathology Laboratory Dr. Moh Hoesin general hospital, Palembang. CRP examination is carried out starting from 1-7 days postoperatively. Participants are grouped between patients who are leakage and nonleakage.

Data analysis was performed with IBM SPSS Version 23. Univariate tests were performed which presented the frequency distribution of demographic and clinical data. Next, a bivariate test was performed to compare CRP levels between the time of examination and between groups of leakage and non-leakage. 


\section{STS SRIWIJAYAJOURNAB OFEURGERY}

\section{Results}

In this study, the mean age in the leakage group was $29.7+9.61$ years, while in the nonleakage group it was $45.47+17.52$ years, but there were no significant differences in the two groups based on the unpaired t test with $p=0.151$. There were no significant differences in sex in the leakage and non-leakage groups based on Fisher's exact test with $p=1,000$. There were no significant differences in the types of operations, namely elective and emergencies in the leakage and non-leakage groups based on Fisher's exact test with $p=0.404$. There were no significant differences in stitching techniques, namely stapler and hand sew in the leakage and non-leakage groups based on Fisher's test with $\mathrm{p}=1,000$. There was no significant difference in diagnosis, namely tumors and non-tumors in the leakage and non-leakage groups based on Fisher's test with $\mathrm{p}=0.566$. There was no significant difference in anastomosis, namely small intestine and colon in the leakage and non-leakage groups based on Fisher's test with $\mathrm{p}=0.307$.

Table 1. Subject Baseline Characteristics

\begin{tabular}{lccc}
\hline \multicolumn{1}{c}{ Characteristics } & Leakage & Non-leakage & P value \\
\hline Age (years) & $29.7 \pm 9.61$ & $45.47 \pm 17.52$ & $0.151^{* *}$ \\
\hline Sex & $2(66.7 \%)$ & $12(70.6 \%)$ & $1.000^{*}$ \\
Male & $1(33.3 \%)$ & $5(29.4 \%)$ & \\
Female & & & $0.404^{*}$ \\
\hline Operation type & $2(66.7 \%)$ & $15(88.2 \%)$ & \\
Elective & $1(33.3 \%)$ & $2(11.8 \%)$ & \\
Emergency & & & \\
\hline Stitching technique & $0(0 \%)$ & $3(17.6 \%)$ & \\
Stapler & $3(100 \%)$ & $14(82.4 \%)$ & \\
Hand Sew & $1(33.3 \%)$ & $10(58.8 \%)$ & \\
\hline Diagnosis & $2(66.7 \%)$ & $7(41.2 \%)$ & \\
Tumor & & & \\
Non-tumor & & & \\
\hline
\end{tabular}




\section{SSS SRIWIJAYA JOURNAB OPSURGERУ}
Anastomosis
Small intestine
$3(100 \%)$
$4(23.5 \%)$
Colon
$0(0 \%)$
$13(76.5 \%)$

$0.307 *$

In this study, the mean CRP of preoperative serum in the leakage group was $53.33 \mathrm{mg} /$ L while in the non-leakage group it was $20.88 \mathrm{mg} / \mathrm{L}$. Based on the Mann-Whitney test there was no significant difference in the mean preoperative serum CRP between the two groups with $\mathrm{p}=$ 0.852. In the leakage group CRP serum increased from the first day postoperatively and reached a peak on the third postoperative day $(242 \mathrm{mg} / \mathrm{L})$ then followed by a rapid decrease until the seventh postoperative day, whereas in the non-leakage group the CRP serum increased from the first postoperative day and reached peak on the second postoperative day $(157.82 \mathrm{mg} / \mathrm{L})$ then followed by a slow decline until the seventh postoperative day. The mean percentage increase in CRP in the leakage group between days 1 to 2, 2 to 3 and 3 to 4 was higher than the non-leakage group, which was $143.4 \%$ vs $80.3 \%, 22,3 \%$ vs $-5.9 \%$ (CRP decreased), and $9.2 \%$ vs $-24.7 \%$ (CRP down). In this study, the mean CRP of preoperative serum up to postoperative day 7 in the leakage group was higher than non-leakage (figure 1), but these results did not show significant differences between the two groups.

Table 2. Pattern Change of CRP

\begin{tabular}{lcccccccc}
\hline \multirow{2}{*}{ Group } & \multicolumn{7}{c}{ Mean CRP (mg/L) } \\
\cline { 2 - 9 } & Preop & POH-1 & POH-2 & POH-3 & POH-4 & POH-5 & POH-6 & POH-7 \\
\hline Leakage & 53.33 & 126.00 & 178.33 & 242.00 & 106.00 & 64.00 & 44.50 & 19.00 \\
Non-leakage & 20.88 & 106.12 & 157.82 & 137.12 & 101.53 & 64.94 & 43.53 & 27.00 \\
$\mathrm{p}^{*}$ & 0.852 & 0.791 & 0.634 & 0.791 & 0.507 & 0.506 & 0.595 & 0.919 \\
\hline
\end{tabular}

Notes : POD: post operation day-; Preop: preoperation; *P Value leakage VS non leakage

On the second postoperative day the mean CRP serum leakage group was $178.33 \mathrm{mg} / \mathrm{L}$ while the non-leakage group was $157.82 \mathrm{mg} / \mathrm{L}$. On the third postoperative day the mean CRP 


\section{SSS SRIWIJAYA JOURNABOPSURGERY}

serum leakage group was $242 \mathrm{mg} / \mathrm{L}$ while the non-leakage group was $137.12 \mathrm{mg} / \mathrm{L}$. However, based on the results of the Receiver Operating Characteristic (ROC) curve analysis, it is obtained that the CRP cut-off value of serum $170 \mathrm{mg} / \mathrm{L}$ on the second postoperative day has a maximum sensitivity (67\%) and specificity (65\%) in predicting the risk of postoperative anastomosis leakage. In this study, 2 subjects (22.2\%) had CRP levels> $170 \mathrm{mg} / \mathrm{L}$ who experienced leakage and 7 subjects (77.8\%) had CRP levels> $170 \mathrm{mg} / \mathrm{L}$ but did not experience leakage. Fisher's test results showed no significant difference between increasing levels of CRP with the occurrence of leakage with a value of $\mathrm{p}=0.566$. More data is presented in table 3 below.

Table 3. The relationship of changes in CRP levels with the occurrence of leakage

\begin{tabular}{cccc}
\hline \multirow{2}{*}{ Group } & \multicolumn{2}{c}{ CRP level } & \multirow{2}{*}{} \\
\cline { 2 - 3 } & $>\mathbf{1 7 0} \mathbf{~ m g / L}$ & $-<\mathbf{1 7 0} \mathbf{~ m g / L}$ & \\
\hline Leakage & $2(22.2 \%)$ & $1(9.1 \%)$ & 0.566 \\
Non-leakage & $7(77.8 \%)$ & $10(90.9 \%)$ & \\
\hline
\end{tabular}

*Fisher test $(\mathrm{p}<0.05)$

\section{Discussion}

In this study, the mean age in the leakage group was $29.7+9.61$ years while in the nonleakage group it was $45.47+17.52$ years. Due to the small number of leakage samples it is not in accordance with a study showing that an increase in age above 60 years can increase the risk of leakage of the intestinal connection.16 In this study it was found that there were 2 male sexes $(66.7 \%)$ in the leakage group and 12 subjects $(70.6 \%)$ in the non-leakage group. Male is more at risk of leakage of the intestine due to a difficult technique to do intestinal junction in men due to the narrow male pelvic cavity. ${ }^{17}$

In this study, there were one type of emergency operation (33.3\%) in the leakage group and 2 subjects $(11.8 \%)$ in the non-leakage group. From 3 emergency cases that were carried out by anastomosis, there was 1 case of leakage compared to elective cases of 2 leaks from 17 anastomosis. Emergency surgery is predicted to be associated with an increased incidence of bowel leakage when compared with elective surgery. ${ }^{18}$ In this study we found 1 subject $(33.3 \%)$ in the 


\section{STS SRIWIJAYAJOURNAB OFEURGERY}

leakage group and 10 subjects $(58.8 \%)$ in the non-leakage group diagnosed with tumors. Tumor size factors that are $>3 \mathrm{~cm}$ or even $>4 \mathrm{~cm}$, advanced tumors and widespread metastases increase the risk of leakage of the intestine connection. ${ }^{19}$ In this study, 13 subjects (76.5\%) colon connections in the non-leakage group while in the leakage group 0 subjects (0\%). A more distal bowel connection has a higher risk of leakage of the bowel joint. ${ }^{20}$

In this study, the mean CRP of preoperative serum in the leakage group was $53.55 \mathrm{mg} / \mathrm{L}$ while in the non-leakage group it was $20.88 \mathrm{mg} / \mathrm{L}$. An increase in preoperative CRP can predict a poor prognosis in patients with hepatocellular, pancreatic and colon cancer. ${ }^{21}$ In the CRP leakage group serum increased from the first day postoperatively and reached a peak on the third postoperative day (242 $\mathrm{mg} / \mathrm{L})$ then followed by a rapid decrease until the seventh postoperative day, whereas in the non-leakage group the CRP serum increased from the first postoperative day and reached the peak on the second postoperative day $(157.82 \mathrm{mg} / \mathrm{L})$ then followed by a slow decline until the seventh postoperative day. These findings are supported by research by Almeida et al which showed the results that the non-leakage group experienced an increase in serum CRP from the first postoperative day and reached a peak on the second postoperative day (132 mg / L) .$^{22}$ In this study, the mean CRP of preoperative serum up to the seventh postoperative day in the leakage group was higher than non-leakage, but these results did not show a significant difference between the two groups. These findings are in line with studies that show that mean CRP postoperative serum for the second day onwards is significantly higher in the leakage group and this marker continues to increase until complications arise. These findings are also consistent with other published studies and show that an increase in initial and ongoing postoperative serum CRP can be used as a predictor of intestinal junction leakage. ${ }^{23}$ The reduction in the average CRP in the leakage group after day 3 post due to at least a small sample and in this case the leakage that was found was grade 1 (not found in clinical sepsis). On the second postoperative day the mean CRP serum leakage group was $178.33 \mathrm{mg} / \mathrm{L}$ while the non-leakage group was $157.82 \mathrm{mg} / \mathrm{L}$. On the third postoperative day the mean CRP serum leakage group was $242 \mathrm{mg}$ / L while the non-leakage group was $137.12 \mathrm{mg} / \mathrm{L}$. However, a cut-off CRP serum value of $170 \mathrm{mg} / \mathrm{L}$ on the second postoperative day had maximum sensitivity (67\%) and specificity $(65 \%)$ in predicting the risk of postoperative bowel leak leakage. These findings are different from the findings of Almeida et al. 
who received a cut-off value of $140 \mathrm{mg} / \mathrm{L}$ with sensitivity (78\%) and specificity (86\%) on the third postoperative day. ${ }^{23}$

CRP is a protein that is specifically synthesized by liver cells as an acute phase response stimulated by IL-6, TNF- $\alpha$, and IL-1 $\beta$. This protein works in endothelial cells and also plays a role in the inflammatory cascade. The short half-life (+19 hours) makes CRP a potential marker for detecting disease activity, inflammatory response and postoperative recovery or a marker for postoperative complications. Changes in postoperative CRP levels in patients who have leakage indicate an inflammatory process and activation of hepatic CRP synthesis immediately after the surgical procedure and have not shown clinical manifestations. However, the synthesis of CRP depends on liver function and there must be no other organ failure and the CRP production ratio actually shows the intensity of an inflammatory process. ${ }^{24}$ Ischemic tissue that occurs in the intestinal joint sutures that leak due to the presence of an initial and intense inflammatory response, which is characterized by increased CRP synthesis. The theory that low tissue perfusion increases the risk of anastomotic complications is shown by several studies. In an experimental model of animals and humans showed a decrease in tissue oxygen pressure that affects the tissue healing process. In addition, a decrease in intramucosal $\mathrm{pH}$ levels in the first 24 hours postoperatively is significantly associated with an increased risk of dehydration. In detecting leakage of intestinal connections. Thus, appropriate treatment steps can be determined so that the morbidity and mortality rates due to complications of the anastomosis can be eliminated.

\section{Conclusion}

Preoperative serum CRP levels up to postoperative $7^{\text {th }}$ day in the leakage group were higher than non-leakage, but there were no significant differences between the two groups.

\section{References}

1. A.B Almeida dan G. faria, Elevated serum C-reactive protein as a predictive factor for anastomotic leakage in colorectal surgery. An International Journal of Surgery, Desember 2011. P:87-91 


\section{SISS SRIWIJAYA JOURNABOPSURGERУ}

2. Hamed ahmed. Anastomosis leakage after gastrointestinal surgery : risk factors, presentation and outcome. The Egyptian Journal of Hospital Medicine, October 2014. P:494-512.

3. Bielecki. K, Gajda. A. The causes and prevention of anastomosis leak after colorectal surgery. Department of General Surgery. Orbowski Hospital Polandia 1999.

4. Ozgen Isik, Tuncay Yilmazlar, Ersin Ozturk. Anastomotic leak after colorectal surgery : leak rate for right hemicolectomy may be higher than expected. Journal Integrative Oncology 2015; 2329-6771.

5. Bodil Gessler, Olle Erikson, Eva angenete. Diagnosis, treatment and consequences of anastomotic leakage in colorectal surgery. International Journal Colorectal disease 2017; 32: $549-556$.

6. Mc.dermott F.D, S. Arora, J. Smith. Prevention, diagnosis and management of colorectal anatomotic leakage. Association of Surgeon of Great Britain and Ireland; March 2016.

7. Broadley G, et all. Using CRP to predict anastomotic leakage after open and laparasopic colorectal surgery: is there a difference?. International journal of colorectal disease. 2016 ; $31: 861-868$.

8. Santonotico C, Et all. C-Reactive protein kinetics after major surgery. Society of critical care Anesthesiologists. 2014 : 119 : 624-6219.

9. Wicaksono E. Incident of leakage in bowel anastomosis in 2017-2018 at Departement of Surgery. Medical Record of Mohammad Hoesin Hospital. Palembang, Indonesia 2018.

10. Cohen J. Everthing you need to know about C-reactive protein. Selfhacked book 2018: vol $1: 2-5$.

11. Wani Imtiaz. Predictive factors for anastomotic leakage after colorectal surgery; Study Protocol for Prospective Observational Study. JMIR Research Protocol, June 2016.

12. S. Michael, David A. margolin. Management of Colorectal Anastomotic leak; Clin Colon Rectal Surgery, 2016; P.29 :138-144

13. Park.JS, Choi GS, Kim SH, Kim HR, Kim NK, Lee KY. Multicenter analysis of risk factor for anastomotic leakage after laparoscopic rectal cancer excision; Korean Laparoscopic Colorectal Surgery Study Group. Annals of Surgery; 2013; 257(4) : 665-671. 


\section{SISS SRIWIJAYA JOURNABOPSURGERУ}

14. Lipska MA, Bisset IP, Parry BR, Merrie AE. Anastomotic leakage after lower gastrointestinal anastomosis: men are at a higher risk. ANZ journal of Surgery; 2006; 76(7): 579-585.

15. Jung SH, Yu CS, Choi PW, Kim DD. Risk factors and oncologic impact of anastomotic leakage after rectal cancer surgery. Disease of the colon and Rectum; 2008; 51(6) : 902908.

16. Damhuis RA, Wereldsma JC, Wiggers T. The influence of age on resection rates and post operative mortality in 6457 patients with colorectal cancer. International Journal of Colorectal disease; $1996: 11(1): 45-48$.

17. Belalla david. Risk of Acute Anastomotic leakage after preoperative radiotheraphy in rectal cancer. Journal of Acute Desease, August 2016; P: 462-465.

18. Cong ZJ, Fu CG, Wang HT, Liu LJ, Zhang W, Wang H. Influencing factors of symptomatic anastomotic leakage after anterior resection of the rectum for cancer. World Journal of Surgery; 2009; 33(6):1292-1297.

19. Golub R, Golub RW, Cantu R, Jr. Stein HD; A multivariate analysis of factors contributing to leakage of intestinal anastomosis. Journal of the American College of Surgeons; 1997 : 184(4) : 364-372.

20. Slicker JC, Komen N, Mannaerts GH, Karsten TM. Longterm and perioperative corticosteroid in anastomotic leakage; a prospective study of 259 left side colorectal anastomosis. Archives surgery $2012 ; 147(5)$ : 447-452.

21. Warschkow R, Steffen T, Thierbach J, Bruckner T. Risk factors for anastomotic leakage after rectal cancer resection and reconstruction with colorectostomy; a restrospective study with boostrap analysis. Annals of Surgical Oncology 2011; 18(10) : 2772-2782.

22. Jestin P, Pahlman L, Gunnarsson U. Risk factors for anastomotic leakage after rectal cancer surgery; a case-control study. Official Journal of The Association of Coloproctology of Great Britain \& Ireland 2008;10(7):715-721.

23. Bakker IS, Grossman I, Henneman D, Havenga K. Risk factors for anastomotic leakage and leak related mortality after colonic cancer surgery in nationwide audit. The British Journal of Surgery; 2014 :101(4): 424-432. 


\section{STS SRIWIJAYA JOURNAB OFEURGERY}

24. Canedo J, Lee SH, Pinto R, Murad-Regadas S. Surgical resection in Chron's disease : is imunosupressive medication associated with higher post operative infection rates ? colorectal disease. The Official journal of the Association of Coloproctology of Great Britain and Ireland 2011; 13 (11) : 1294-1298.

25. Krane MK, Allaix ME, Zoccali M, Umanskiy K. Pre operative infliximab therapy does not increase morbidity and mortality after laparoscopic resection for inflammatory bowel disease; disease of the colon and rectum; $2013: 56(4): 449-457$. 